\title{
Assessment of Water Resources and Analysis of Safe Yield and Reliability of Surface Water Reservoirs of Asmara Water Supply System
}

\author{
Kahsay N. Zeraebruk ${ }^{1}$, Alfred O. Mayabi ${ }^{1} \&$ John M. Gathenya ${ }^{1}$ \\ ${ }^{1}$ College of Engineering and Technology, Jomo Kenyatta University of Agriculture and Technology, Kenya \\ Correspondence: Kahsay Zeraebruk, Department of Civil Construction and Environmental Engineering, JKUAT, \\ P.O. Box 62000-00200 Nairobi. Tel: 254-708-725-239. E-mail: kahsayneg2000@gmail.com \\ Received: January 5, 2017 \\ Accepted: January 17, 2017 \\ Online Published: February 6, 2017 \\ doi:10.5539/enrr.v7n1p45 \\ URL: http://dx.doi.org/10.5539/enrr.v7n1p45
}

\begin{abstract}
In a water supply system safe yield is the average annual volume that can be supplied to the system subject to an adopted set of operational rules and a typical demand pattern without violating a given level of service standard. It is dependent upon storage and hydrologic (rainfall/runoff/evaporation) characteristics of the sources, the source facilities, upstream and downstream permitted withdrawals and minimum in-stream flow requirements.

For effective operation and management of a water supply system, it is important to have knowledge of water balance of the reservoirs and estimate their safe yield at a certain level of reliability. In this study, to assess water resources potential of existing surface water sources and new catchments and estimate the water balance of the water supply system, the hydrologic simulation model, SWAT (Soil and Water Assessment Tool) was utilized. The model was calibrated and validated successfully. The safe yield and corresponding reliability of reservoirs were estimated using a deterministic water balance model. The results of the water balance analysis and projected water demand were used to assess existing water supply situation and challenges in future. The assessment indicated that the gap between demand and supply at high population growth rate scenario is wide and very critical.

To close the gap between the available water supply and the increasing water demand in the study area, utmost attention is needed by the decision making authorities and the management of the water utility to improve performance efficiency of the water supply system by instituting effective water governance and reducing leakage losses.
\end{abstract}

Keywords: Safe yield, SWAT, reliability, water demand, population growth and projection, decision support tool

\section{Introduction}

In a water distribution system, the purpose of a water supply reservoir is to balance differences between supply and demand. The temporal variation of storage is a function of several variables such as inflow, outflow and losses. The yield or outflow from a reservoir or a group of reservoirs depends on the active storage capacity of each reservoir and the water that flows into each reservoir, i.e., the inflow (Ahmed, Srivastava, \& Rani, 2013). Hence, in order to effectively utilize the water reservoirs for different purposes such as water supply, hydropower generation, irrigation, and flood control, knowledge of water quantity within the reservoir is required (Yunus \& Fidelia, 2012). In other words, the balancing or buffering ability of a reservoir is limited by its maximum capacity and its current storage volume at the beginning of the cycle. Under normal circumstances, the configuration and size of a reservoir system impose the primary constraints on how much surface runoff can be controlled in a river basin. In addition, regional hydrology plays a critical role in determining how well the water stored in reservoirs may be regulated.

Reservoir safe yield is generally defined as the reliable withdrawal rate that can be provided by a combination of streamflows and reservoir storage through a defined critical drought period. In a water supply system the safe yield is the average annual volume that can be supplied to the system subject to an adopted set of operational rules and a typical demand pattern without violating a given level of service standard. Safe yield is dependent upon storage and hydrologic (rainfall/runoff/evaporation) characteristics of the sources, the source facilities, 
upstream and downstream permitted withdrawals and minimum in-stream flow requirements. However, as the relationship between storage size and reservoir yield needs to be specified in a reservoir storage-yield analysis it is a straightforward exercise to interchange these two variables (McMahon, Pegram, Vogel, \& Peel, 2007).

Storage reservoirs tend to be large and complex systems requiring equally complex mathematical models to simulate their behaviour (Vogel \& Bolognese, 1995). Quantitatively, reliability of a water reservoir is defined as the percentage of time that the water supply system is able to meet the full demand. Therefore, deficiency is defined as not meeting the full demand. An adaptive management strategy is needed when one has to make a decision on the face of uncertainty and have a chance to learn from management decisions through careful monitoring of key variables (Asefa, Adams, \& Wanakule, 2015). Such condition would result in water use restrictions until the water supply system is again able to meet all quantitative criteria. To fully understand the ecologic, geomorphologic, and hydrologic impacts of dams, it is necessary to integrate our knowledge of all factors that influence their operational behaviour (Vogel et al., 2007).

One of the main aspects of the safe yield and reliability analysis is water demand. Estimating and forecasting water demand become necessary as the urban population dependent on public water supplies increases rapidly and new demands for water are not easily met. Considerable efforts have been put into the development of urban water supply projections in the last four decades resulted in a wealth of understanding and sophisticated forecasting techniques in this field (Okeola, Balogun, \& Bell, 2015). Different kinds of data-sets have been used and the quantity and type of data available determine which forecasting method should be considered for application. There is no absolute level of accuracy that is appropriate in all demand forecasting situations (Okeola et al., 2015).

Analysis of demand for water in Least Developed Countries (LDCs) is complicated by abundant evidence that, contrary to what is observed in most developed countries, households in LDCs have access to and may use more than one of several types of water sources, such as in-house tap connections, public or private wells, public or (someone else's) private taps, water vendors or resellers, tank trucks, water provided by neighbours, rainwater collection, or water collected from rivers, streams, or lakes (Nauges \& Whittington, 2009).

Scarcity and unsustainable use of water resources have become the major critical developmental issues throughout the world. Population growth increases demand and competition for water resources and compounds water scarcity. Sub Saharan Africa is projected to be severely impacted by water scarcity because of climate change (Mutunga, Zulu, \& De Souza, 2012). The problem of water is further exacerbated by relatively high annual population growth rates. Mutunga et al. (2012) stated that, fifteen countries in Sub Sahara Africa, which are home to about 400 million people, are suffering from water scarcity or water stress. Further the report by Mutunga et al. (2012) indicated that most of the water stressed and scarce countries in Africa had recorded high population growth rates (including Eritrea) showing growth rates as high as 3.2 percent per year. The high population growth rates combined with anticipated changes in climate would result in water shortages to likely become even more severe, especially in areas where economic and political problems impede access to fresh water.

Eritrea had the third highest urban population growth rate in Africa for the years 2000-2005, where the annual urban population growth was 6\% (Tewolde \& Cabral, 2011). Reports indicate that Asmara was one of the fastest growing cities in Africa. The growth of the city has also been witnessed through surface area growth by incorporating most of the villages around the city. As a result, the Greater Asmara Area (GAA) has experienced high population growth in the past two decades, particularly, after the independence of the country in 1991 (Tewolde \& Cabral, 2011).

Ensuring a water supply utility's ability to be there when needed in the future is far from exact science; consequently one of the most challenging tasks of water supply utilities is planning the timing and quantity of new water supply sources as demand for water consumption grows (Asefa et al., 2015).

\section{Description of the Study Area}

This study is based on Asmara water supply system. Asmara is the capital of the state of Eritrea and the administrative centre of the Central Region known as Administration of Maekel Zone (AMZ). Asmara is located at an average elevation of $2350 \mathrm{~m}$ above mean sea level in the central highlands of Eritrea, Figure 1.

As a capital city and major business centre, Asmara has been growing relatively faster in recent years in surface area and population. Records indicate that the current population of Asmara, including the satellite villages, to be around 450,000 (Database of AMZ, 2012). Asmara Water Supply and Sewerage Department (AWSD) is the only public utility responsible for water and sewerage services in and around Asmara. 
Systematic development of water supply and management in Eritrea dates back to the colonial times. The Italian colonial administration developed domestic water supply as part of overall programme to improve the level of personal hygiene and environmental sanitation in the major towns of Eritrea, especially in the capital city, Asmara. This is evident as some of the water supply infrastructure facilities currently in use for supplying water to the capital were built during the colonial period.

The major source of water supply for Asmara is surface water produced from rainfall occurring mainly during the rainy months of July-September. The runoff created over the drainage areas joins streams and rivers and finally collected into reservoir dams located around the city. The current water supply and management situation in Asmara and the surrounding villages are constrained due to several problems attributed to drought as well as low technical and financial performance of the water utility.

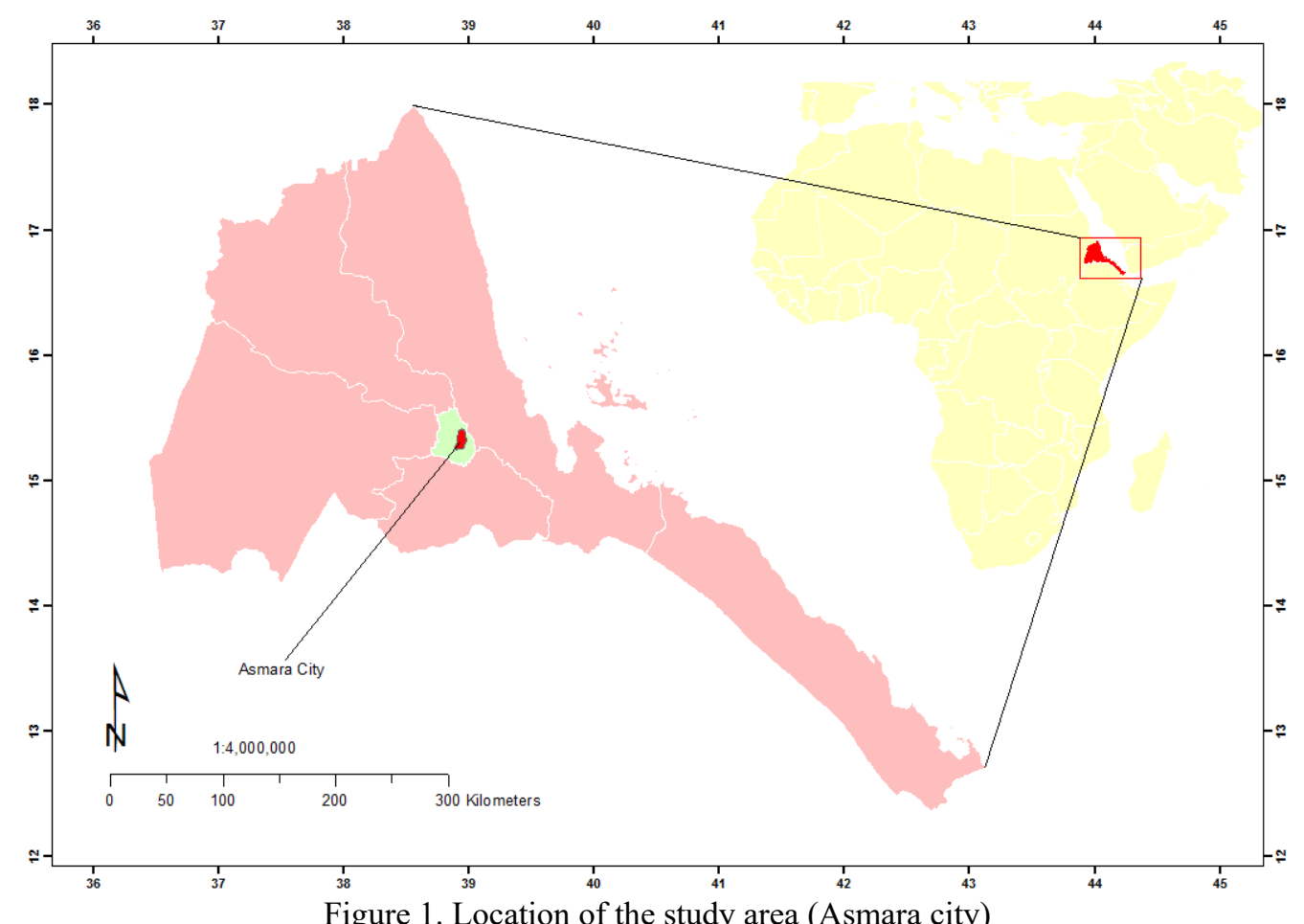

Figure 1. Location of the study area (Asmara city)

Dams have been constructed across a number of streams and rivers to impound the seasonal runoff. The surface water reservoirs currently supplying water to Asmara and surrounding areas are: Mai-Nefhi, Toker, Adi-Sheka, Mai-Sirwa, and Struatta-Vaudetto (Figure 2).

There are three water treatment plants currently under operation. Mai-Nefhi treatment plant is situated just downstream of the Mai-Nefhi reservoir. The raw water from Adisheka, Stretta-Vaudetto and Maiserwa is treated at the oldest treatment plant known as Stretta-Vaudetto WTP. The water from Toker Dam is pumped to a distance of $10 \mathrm{~km}$ to the new treatment plant of Adi-Nifas located next to Stretta-Vaudetto WTP.

Ground water has not been exploited as a direct source of the municipal water. This could be attributed to the quality problem which is mostly brackish in nature. Upon detailed assessment and quantity and quality investigation ground water may be utilized for different purposes which require lesser quality of water.

Small quantities of water are currently obtained from ground water aquifers in the city. Many private wells exist in Asmara serving as either alternative or supplemental sources to the municipal supply. The well fields are located in the eastern and southern areas of Asmara, and abstract water from the zone between relatively recent surface basalts and the underlying weathered laterite (Ethiopia Water Supply and Sewerage Authority, 1985). The quality of this water is variable, having brackish taste at times. The water from the ground water is mostly used for irrigation of small areas of land for vegetable growth.

Three new catchments, within the Central Regional Administration, were identified as potential water supply sources for the future. These are: Ungula catchment, Dem-Sebay Catchment and Aba-Buruk catchment (Figure 3). 


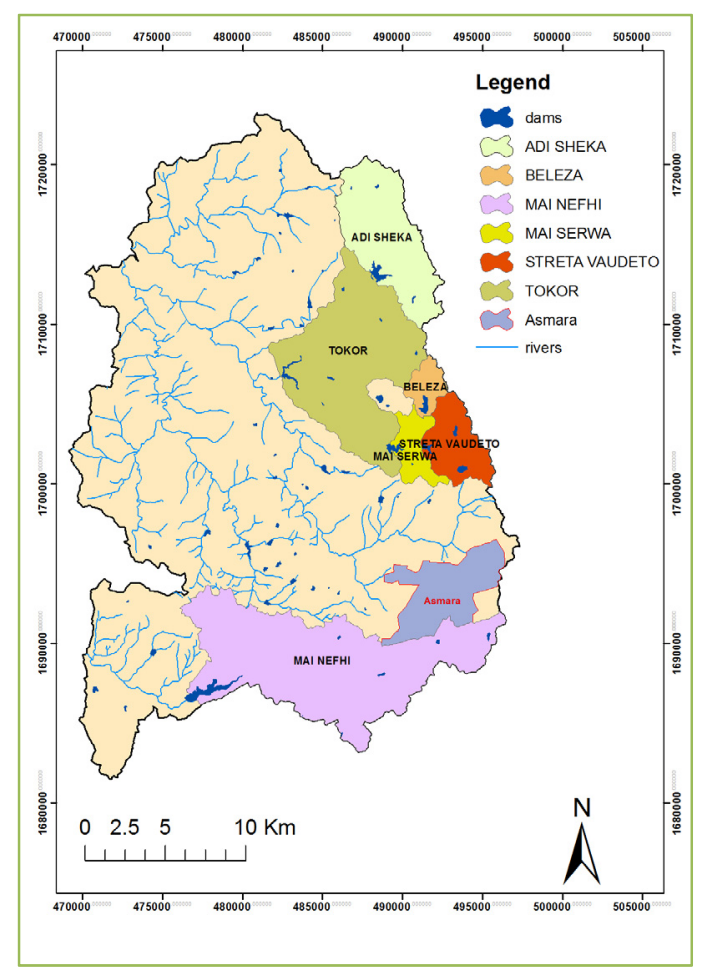

Figure 2. Catchment areas developed for Asmara water supply

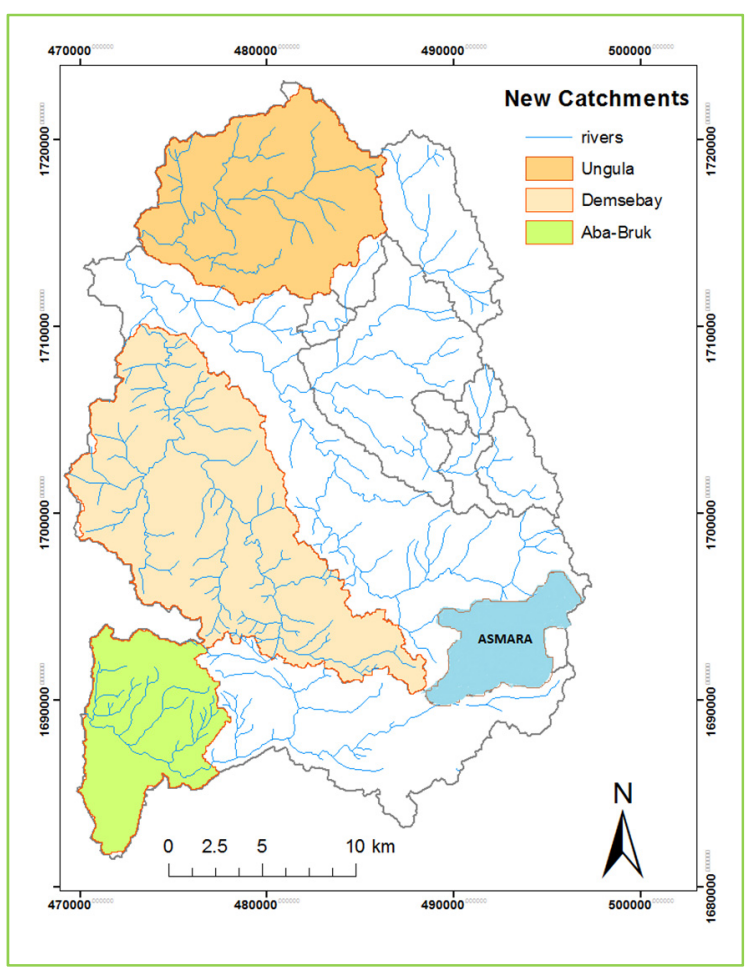

Figure 3. Catchment areas for future water sources development

The surface water sources are dependent on streamflow created from rainfall during the rainy months of mostly July to September. The recurrent drought, evaporation loss during the long dry months and seepage loss from the reservoirs must be taken into account when trying to estimate the water budget of the catchment areas and reliability of safe-yield of the water supply system.

\section{Methodology}

\subsection{Water Resources Analysis}

For planning and decision making purposes and to get reliable information of the water resources potential of catchment areas, hydrological analysis was carried out on existing surface sources with hydrological simulation model, Soil Water Assessment Tool (SWAT). It is a basin scale, continuous time model that operates on a daily time step and is designed to predict the impact of land management practices on water, sediment and agricultural chemical yields in large complex both gauged and un-gauged watersheds with varying land use and management conditions over a long periods of time (Neitsch et al., 2011). Digital elevation model (DEM), weather data, soil data and land use/land cover data are the most important data input for the setup of the SWAT model and for the simulation of the hydrological components (Fiseha, Setegn, Melesse, Volpi, \& Fiori, 2010). The calibrated hydrological model, SWAT, was used to estimate the streamflow hydrograph of the catchment areas.

For purposes of planning and future development schemes, hydrological analysis using SWAT was also carried out on the catchments identified as future sources of water for Asmara. Field investigation by the researchers and experts from Eritrea Water Resources Department indicated that the catchments are well qualified technically for development by constructing dams. Annual stream inflow volumes for each of the catchment areas were estimated using the hydrological model, SWAT.

\subsection{Safe Yield Estimation}

For each of the surface water supply reservoir, safe yield was estimated through the use of a deterministic computer model developed with Microsoft Excel software. The spread-sheet model is a mass balance model developed on the basis of simple accounting (addition and subtraction) of the change in reservoir volume or storage as a function of surface water inflow, withdrawal (outflow), and losses due to evaporation. The model performs calculations and logical functions in a sequential manner temporally on monthly time-step. The calculations and logical functions normally begin using values from the first month of the period of record and 
are repeated for every month until the end of the period of record, with each time beginning with the previous time's ending storage values.

The attainable safe yield during the period of analysis was found by iteration of the monthly mass balance equation for each of the reservoirs. Monthly accounting of water volumes for each reservoir adheres to the following general algorithm:

Ending Storage $=$ Beginning of storage + Natural inflow + Pumped/diverted inflow - water supply release/deliveries - Evaporation - Minimum instream flow

For the surface water reservoirs of Asmara water supply system, the model calculation uses the storage equation concept as developed from the basic mass balance storage equation as:

$$
I_{t}-O_{t}=\Delta S_{t}
$$

Where:

$I_{t}=$ total inflow volume to the reservoir during a specified time period

$O_{t}=$ the total outflow which is the sum of the volume withdrawal (demand) and the volume losses due to evaporation from the reservoir during the time step $t$.

$\Delta \mathrm{S}_{\mathrm{t}}=$ change in storage volume of the reservoir during the specified time period

The mass balance equation can be converted to a form that can analyse the cumulative effects of inflows and outflows over consecutive time steps as follows:

$$
\Delta S_{t}=S_{t+1}-S_{t}
$$

Where:

$\Delta \mathrm{S}_{\mathrm{t}}=$ change in storage of the reservoir during time step $\mathrm{t}$

$\mathrm{S}_{\mathrm{t}+1}=$ storage of the reservoir volume at the end of time step $\mathrm{t}+1$

$\mathrm{S}_{\mathrm{t}}=$ storage of the reservoir volume at the end of time step $\mathrm{t}$

By substituting this relationship, equation 3.2 is transformed to:

$$
\begin{gathered}
I_{t}-O_{t}=S_{t+1}-S_{t} \\
O_{t}=D_{t}+E_{t}
\end{gathered}
$$

$D_{t}=$ the total volume of water withdrawn to satisfy the demand during the time step $t$

$\mathrm{E}_{\mathrm{t}}=$ the total volume of evaporation loss form the reservoir surface area during the time step $\mathrm{t}$.

Equation 3.6 and 3.7 can be combined to a more useful form of the mass balance model as:

$$
S_{t+1}=S_{t}+I_{t}-D_{t}-E_{t} \quad\left(\text { for } S_{\min } \leq S_{t+1} \leq S_{\max }\right)
$$

$\mathrm{S}_{\min }=$ the minimum capacity of the reservoir below which withdrawal is not allowed

$\mathrm{S}_{\max }=$ the maximum capacity of the reservoir

Estimation of the rate of evaporation from the reservoirs was done using the FAO CROPWAT 8.0 Software. CROPWAT 8.0 for Windows is a computer programming model for the calculation of important irrigation parameters such as evapotranspiration.

The evaporation, $\mathrm{E}_{\mathrm{t}}$, was estimated based on the original Penman-Monteith equation and the equations of the aerodynamic and surface resistance. The Penman-Monteith method to estimate $E_{t}$ is expressed as:

$$
E_{t}=\frac{0.408 \Delta\left(R_{n}-G\right)+\gamma \frac{900}{T+273} U_{2}\left(e_{s}-e_{a}\right)}{\Delta+\gamma\left(1+0.34 U_{2}\right)}
$$

where:

$E_{t}=$ reference evapotranspiration $\left[\mathrm{mm} \mathrm{day}^{-1}\right], \mathrm{R}_{\mathrm{n}}=$ net radiation at the crop surface $\left[\mathrm{MJ} \mathrm{m}^{-2}\right.$ day-1],

$\mathrm{G}=$ soil heat flux density [MJ m${ }^{-2}$ day-1], $\mathrm{T}=$ mean daily air temperature at $2 \mathrm{~m}$ height $\left[{ }^{\circ} \mathrm{C}\right]$,

$\mathrm{u}_{2}=$ wind speed at $2 \mathrm{~m}$ height $\left[\mathrm{m} \mathrm{s}^{-1}\right], \mathrm{e}_{\mathrm{s}}=$ saturation vapour pressure $[\mathrm{kPa}]$,

$\mathrm{e}_{\mathrm{a}}=$ actual vapour pressure $[\mathrm{kPa}], \mathrm{e}_{\mathrm{s}}-\mathrm{e}_{\mathrm{a}}=$ saturation vapour pressure deficit $[\mathrm{kPa}]$,

$\Delta=$ slope of vapour pressure curve $\left[\mathrm{kPa}^{\circ} \mathrm{C}^{-1}\right], \gamma=$ psychrometric constant $\left[\mathrm{kPa}^{\circ} \mathrm{C}^{-1}\right]$. 
The monthly volume of reservoir evaporation Evt is a function of the rate of evaporation and the free surface area of the reservoir, $\mathbf{A}$, exposed to the atmosphere; and it was estimated as:

$$
E v_{t}=E_{t} x A
$$

The storage of the reservoir control point is repetitively calculated on a monthly basis by adding total monthly inflows and subtracting total monthly outflows. The total monthly inflows to reservoir are obtained from historical records if the river is gauged otherwise estimated with the hydrological simulation model SWAT. The total monthly outflows from a reservoir are typically calculated by summing monthly withdrawals or releases from the reservoir to serve customer demands.

The model can be beneficial for regulators and managers of Asmara Water Supply utility as a decision-making tool for effective and efficient management of the water supply system.

\subsection{Reservoir Reliability Model}

The simulation was constructed around a flow distribution logic that defines how the system will operate and provides criteria that defines how monthly water demands will be met based on the monthly streamflow, evaporation losses, and previously stored water. The logic is applied to each time step in the simulation as shown in Figure 4.

Periods when the reservoir was less than or equal to the minimum storage capacity $\left(\mathrm{S}_{\mathrm{t}+1}>\mathrm{S}_{\mathrm{mi}}\right)$ were noted and the time based reliability is obtained using:

$$
R_{e}=\left[\frac{\sum D E i}{N}\right] 100
$$

Where $\mathrm{R}_{\mathrm{e}}(\%)$ is the reliability of the reservoir, $\Sigma \mathrm{DE} \mathrm{i}_{\mathrm{i}}$ is the sum of months when the reservoir storage is greater than $\mathrm{S}_{\min }$ (demand-met), and $\mathrm{N}$ is number of months in the simulation period.

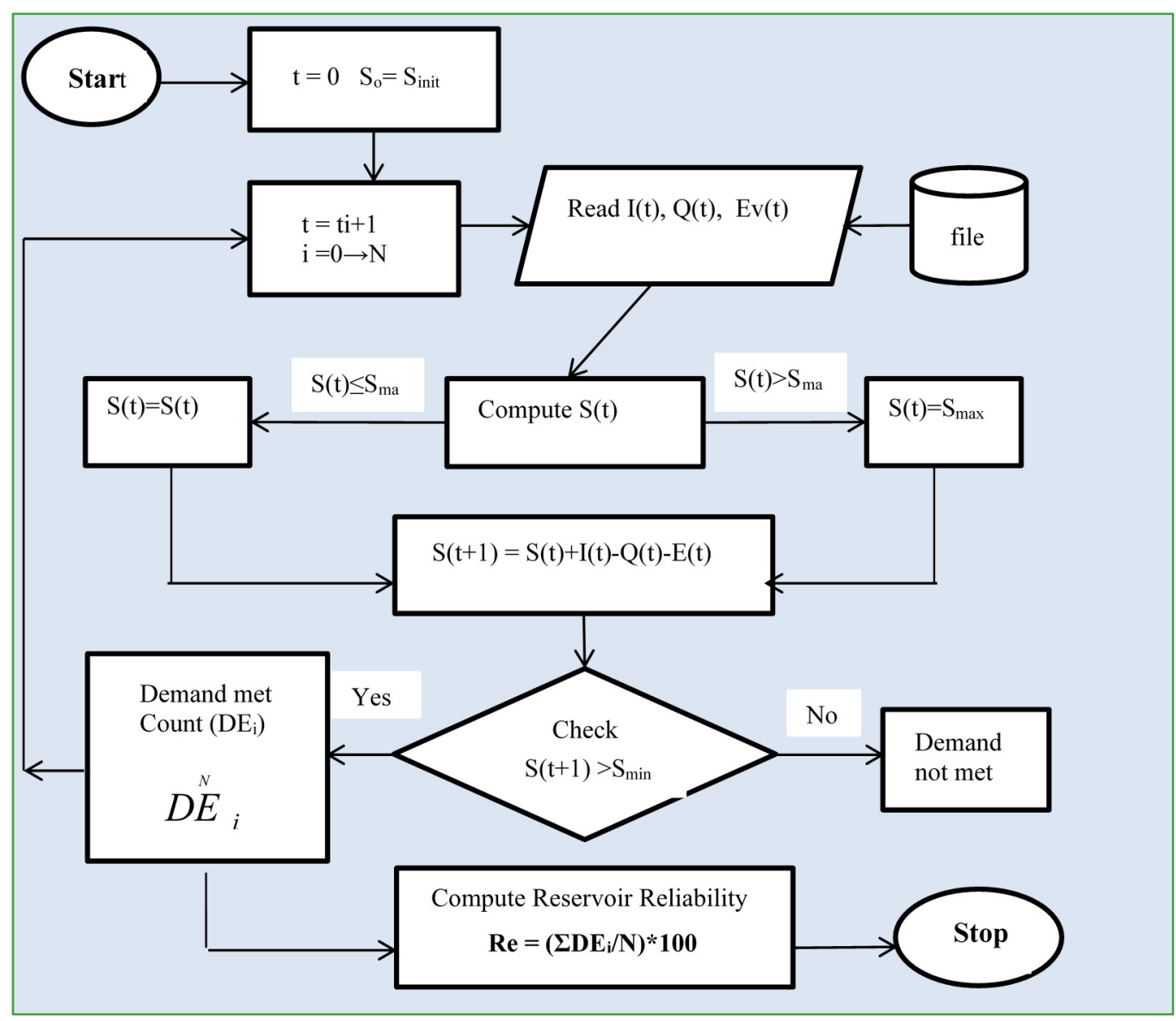

Figure 4. Reservoir Reliability analysis flow diagram 


\subsection{Water Demand Estimation}

Accurate water demand forecasting is an essential ingredient in water resources planning. Future growth in the water demand depends on many factors. The traditional approach of hydrologists and water resources engineers has been to focus on the supply side and the assessment of available water resources

The model developed here to estimate municipal water demand uses a simple purpose-specific process considering the population growth (the number of potential subscribers) and growth per capita water demand as major factors affecting the water requirements in the study area without considering the socio-econometric factors.

\subsubsection{Population Estimation and Forecasting}

Government policymakers and planners around the world use present population sizes and population projections to gauge demand for food, water, energy, and other public services for now and for the future. The size, composition, and distribution of populations and forecasting future demographic characteristics are part of any analysis of sustainable development challenges and opportunities (Mutunga et al., 2012). Knowledge of the current size of the population, its characteristics and the expected growth in the future is one of the important tools required for decision making process.

The report by UN-Habitat 2014 shows that the decade average rate of change in urban population for Eritrea is relatively high, estimated: at $4.22 \%(1970-80), 5.30 \%(2000-10), 4.75 \%(2010-20)$, and projected at $4.03 \%$ (2020-30), 3.56\% (2030-40) and 3.07\% (2040-2050) (UN-Habitat, 2014).

In order to plan for the future water demands of the population of Asmara (the City and satellite villages), it is important to define the demographics and how the population trends are anticipated to change over time.

The population data collected from the database of Administration of Central Region for 2005 and 2010 indicates that the population of Asmara and the satellite villages was around 420,000 and 460,000 respectively (K. Zeraebruk, Mayabi, Gathenya, \& Zemenfes, 2014). These data were used as baseline for future projections. In this study the Geometric Increase Method was used as a model for population projection. In this method, the annual percentage increase or percentage growth rate is assumed to be constant for a given forecast period, and the increase is compounded over existing population. The model is based on the following equation.

$$
P_{t}=P_{o}(1+r)^{t}
$$

Where:

$P_{t}=$ Population projected after $t$ years, $P_{o}=$ Base year population, $r=$ Growth rate $(\% /), t=$ time in years;

The growth rate $(r)$ has been acquired from UN Population estimation and projection made for Eritrea, from 1950 to 2100 for two growth rate scenarios: Moderate-variance growth rate and high-variance growth rate (UN, 2013).

Table 1. Population growth rate for Asmara (UN forecast 2013)

\begin{tabular}{llllllll}
\hline Year & 2015 & 2020 & 2025 & 2030 & 2040 & 2050 & 2060 \\
\hline Medium Variance growth rate (\%) & $3.3 \%$ & $2.8 \%$ & $2.6 \%$ & $2.4 \%$ & $2.1 \%$ & $1.7 \%$ & $1.4 \%$ \\
High Variance growth rate (\%) & $3.4 \%$ & $3.0 \%$ & $2.6 \%$ & $2.7 \%$ & $2.4 \%$ & $2.2 \%$ & $1.8 \%$ \\
\hline
\end{tabular}

The growth rates as predicted by (UN, 2013), and adopted in this study, for the projection of the population in Asmara with medium-variance growth rate and high-variance growth rate are summarised in Table 1 and Figure 5. 


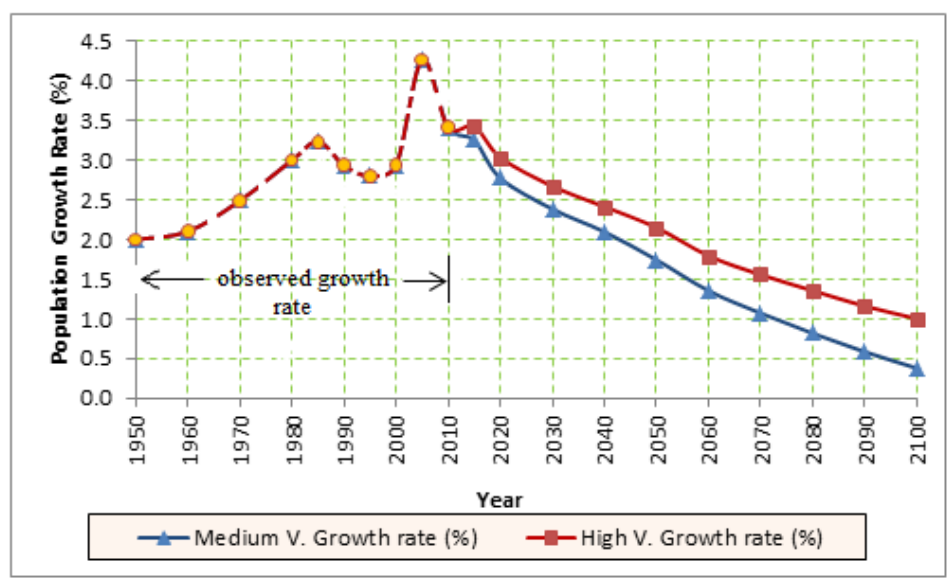

Figure 5. Projected growth rate of population for Asmara (Source: UN, 2013)

Using the population-growth model and the annual growth rate extracted from the UN data, the population of Asmara (including the village around the city) has been estimated and projected up to the year 2060 under moderate-variance and high-variance growth rates. The results of the model are shown in Figure 6.

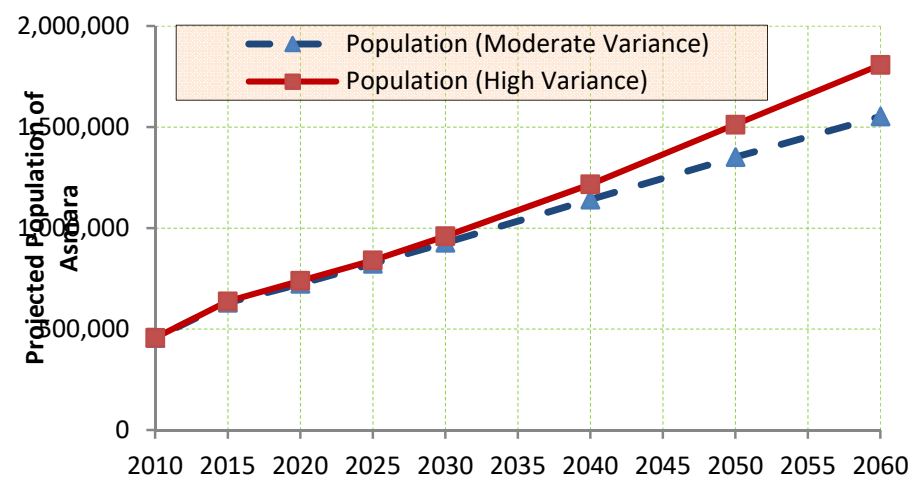

Figure 6. Population projection for Moderate and high variance scenario

\subsubsection{Water Demand Analysis}

The model developed here to estimate municipal water demand uses a simple purpose-specific process considering the population growth (the number of potential subscribers) and growth per capita water demand as major factors affecting the water requirements in the study area without considering the socio-econometric factors.

The study report under 'Technical and Institutional Rehabilitation Study of Asmara Water Supply System', SAUR Intenational and BRL ingenierie (1997) devised a conceptual water demand model, which calculates consumption at each unit zone of the project area as follows:

$$
\begin{gathered}
d_{i}=\text { dom }_{i}+\text { non-dom }_{i} \\
D=\sum d_{i}(1+\% \text { Leakage })
\end{gathered}
$$

Where

$d_{i}=$ demand of a unit zone, $d{ } m_{i}=$ domestic consumption of zone I

$\%$ Leakage $=$ percentage of physical losses, $D=$ overall demand to be supplied (production)

non-dom $_{i}=$ non-domestic consumption of zone i i.e. small industries and large consumers

From these definitions, we underline that the water drawn at a connection point is the consumption and that the corresponding demand is the consumption plus the losses. 


\section{Results and Discussion}

\subsection{Assessment of the Water Supply Sources}

Urban water supply must be operated with high degree of reliability in most cases between 80 to 90 per cent. Since demand for water is always increasing with time, keeping such a high reliability of water supply system requires effective water resources management and strategic planning.

The river catchment areas currently used for Asmara water supply are Adi-Sheka, Stretta-Vaudetto, Mai-Sirwa, Mai-Nefhi and Toker all of them located within the boundary of Central Regional Administration.

The outcome of simulation analysis with the yield-reliability model of existing surface water reservoirs of Mai-Nefhi, Toker Adi-Sheka, Mai-Sirwa, and Stretta-Vaudetto and are shown in Figure 7.

The water supply from the reservoirs has been estimated considering safe yield of $80 \%$ reliability. This means that there is a risk of 1 out of 5 for the reservoirs to fail meeting the water demand. The safe yield of each of the existing water supply reservoirs at $80 \%$ reliability is summarised in Table 2 . With this level of reliability, the results showed that the total water supply capacity of the existing reservoirs was around $43,000 \mathrm{~m}^{3} /$ day.

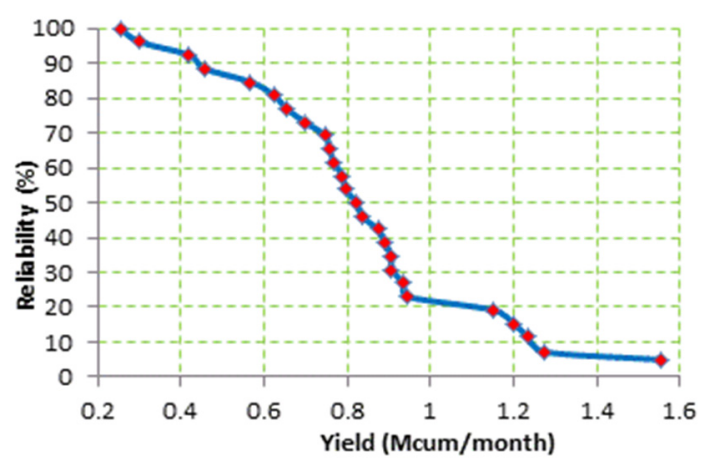

(a) Mai-Nefhi Reservoir

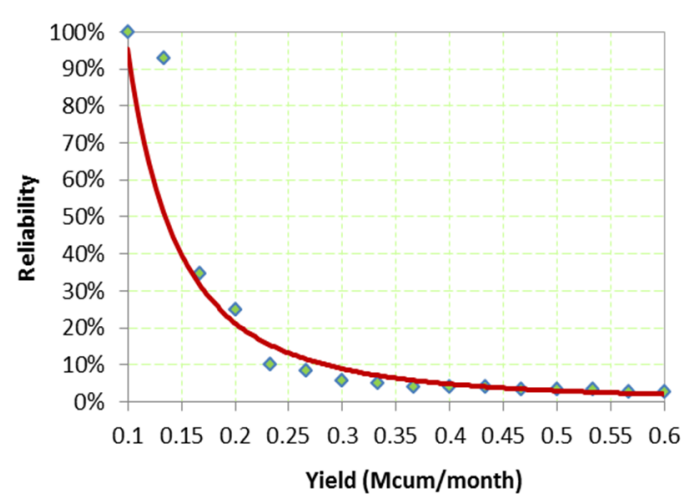

(c) Adi-Sheka Reservoir

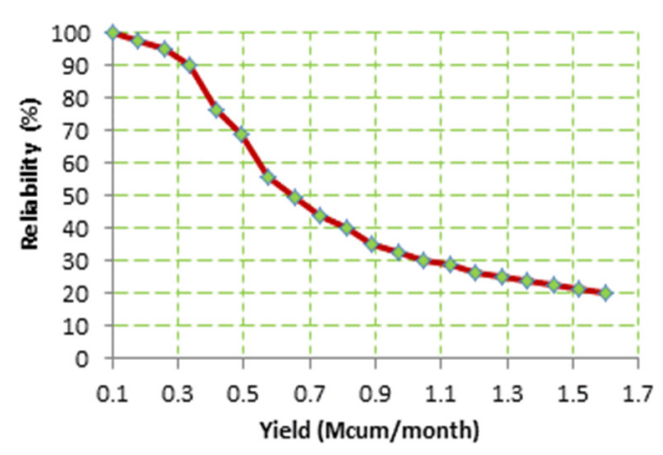

(b) Toker Reservoir

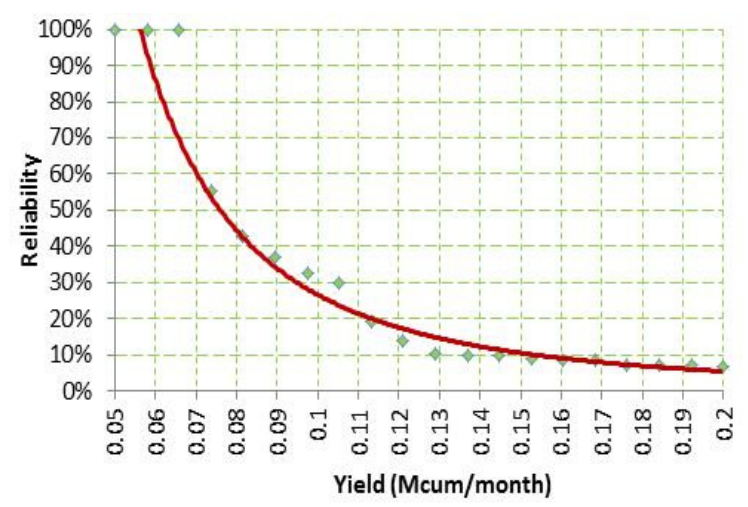

(d) Mai-Sirwa Reservoir

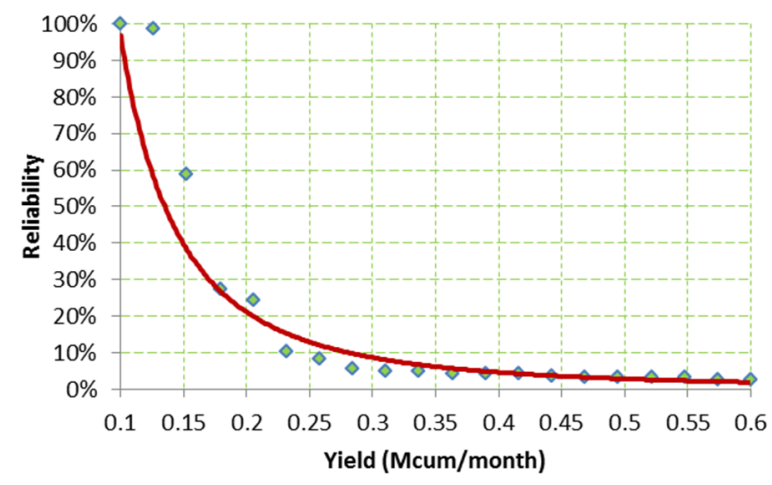

(e) Stretta-Vaudetto reservoir

Figure 7. Yield- reliability curves for the surface water reservoirs of Asmara 
Table 2. Summary of water supply yield of the existing reservoirs

\begin{tabular}{llrr}
\hline \multirow{2}{*}{ No } & Reservoir Name & \multicolumn{2}{c}{ Safe Yield (80\% Reliability) } \\
\cline { 3 - 4 } & & $\mathrm{m}^{3} / \mathrm{month}$ & $\mathrm{m}^{3} /$ day \\
\hline 1 & Toker & 400,000 & 13,300 \\
2 & Adi-Sheka & 117,000 & 3,900 \\
4 & Stretta-Vaudetto & 112,000 & 3,733 \\
5 & Mai-Nefhi & 600,000 & 20,000 \\
6 & Mai-Sirwa & 62,000 & 2,067 \\
SUM & & $1,291,000$ & 43,000 \\
\hline
\end{tabular}

\subsection{Assessment of Future Water Supply Sources}

Three new catchment areas, within the Central Regional Administration, were identified as potential water supply sources for the future. These are: Ungula catchment, Dem-Sebay Catchment and Aba-Buruk catchment (see Figure 3).

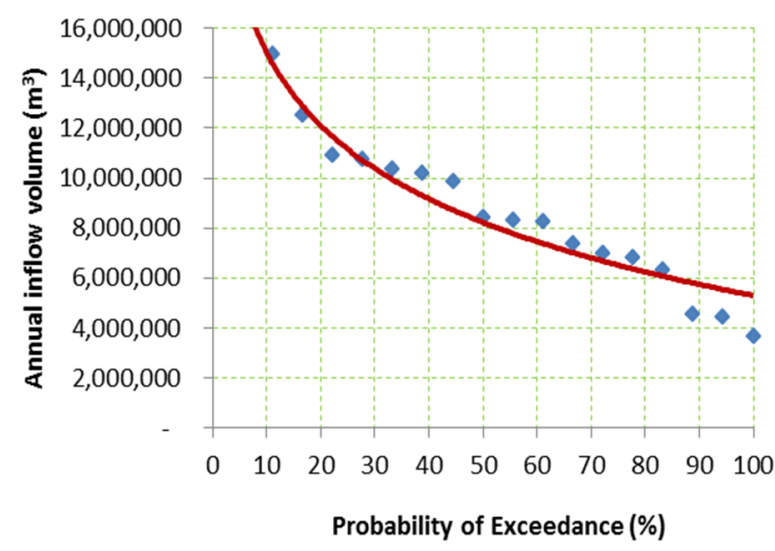

(a) Ungula catchment area

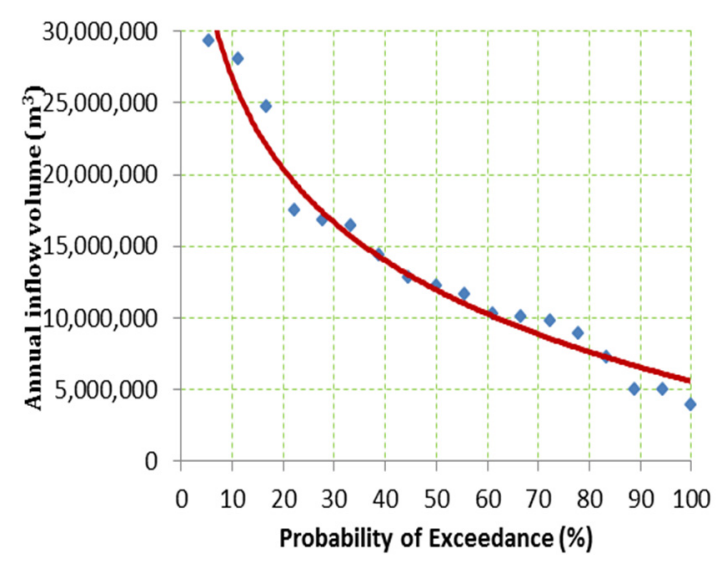

(b) Dem-Sebay catchment area

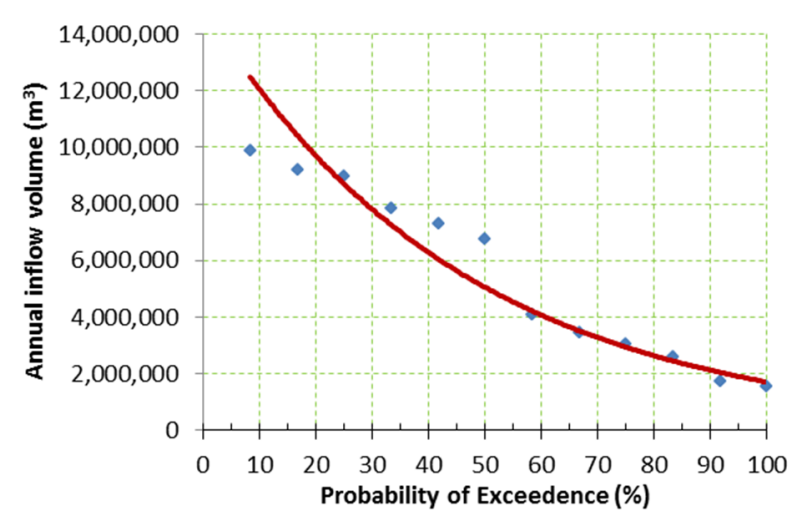

(c) Aba-Buruk catchment area

Figure 8. Flow Duration Curve (FDC) for future water supply sources for Asmara

The calibrated hydrological model, SWAT, developed in this study was used to estimate the streamflow hydrograph for these catchment areas. Each area was delineated with DEM data and the other input data required to running the model such as, weather, soil, land-use/cover, were used to predict the monthly streamflow expected in each of the catchment areas, as discussed in the following sections.

For each of the three catchments the flow duration analysis was conducted and the results of the probability of exceedance analysis for Ungula, Dem-Sebay and Aba-Bruk are summarised in Figure 8. 
Streamflow analysis with the hydrological model (SWAT) indicated that the Ungula, Dem-Sebay and Aba-Bruk catchment areas could deliver around 6.0, 8.0 and 3.0 Mcum of water every year at $80 \%$ of probability of exceedance (Figure 8).

\subsection{Water Demand Projection}

The amount of water needed by consumers (water demand) depends on the population to be served and the rate of per capita water consumption. Both this parameters are time dependent and in most cases they tend to grow with time which is true for cities in developing countries such as Asmara.

The conceptual water demand model was used to simulate the future water demands projected up to 2060 for the moderate -variance and high-variance growth rates. The growth in per capita demand assumed and the corresponding daily per capita demand $(1 / \mathrm{c} / \mathrm{d})$ for the moderate and high population growth scenarios are shown on Figure 9.

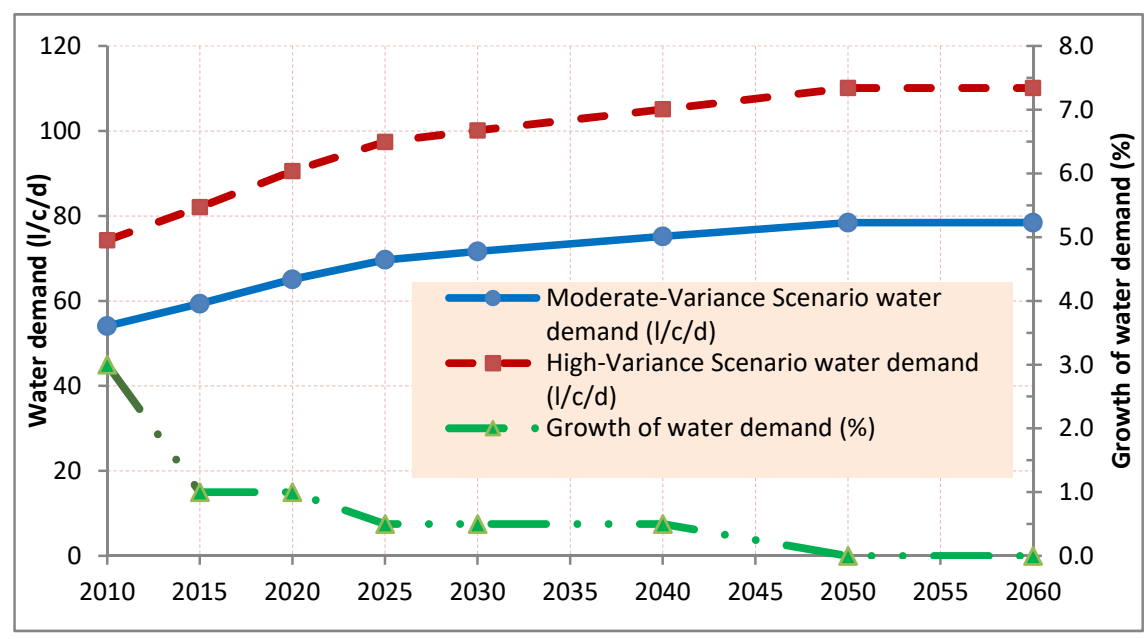

Figure 9. Projected daily per capita demand and water demand growth rate

The projected daily water demand for the moderate growth rate scenario and high growth rate scenario are shown in Figure 10.

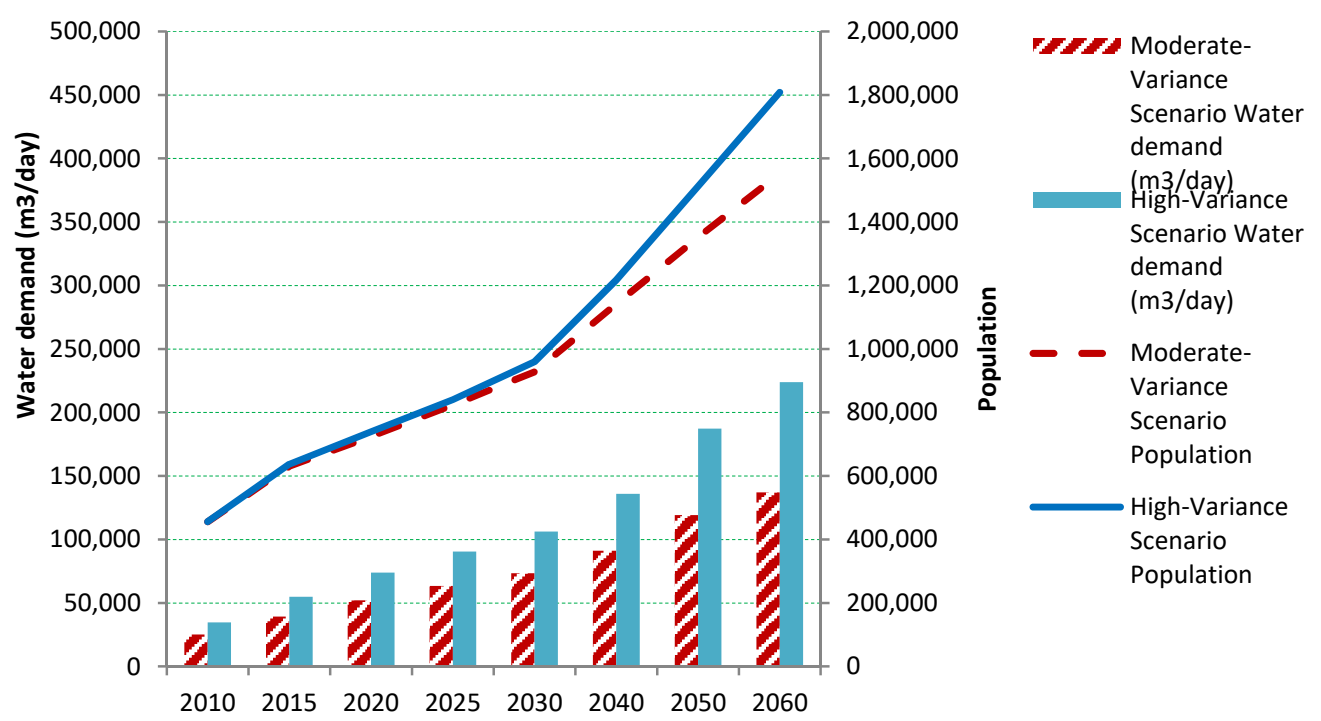

Figure 10. Asmara City projected population and daily water demand 


\subsection{Comparison of Safe Water Supply Yield and Demand}

The water supply potential of the surface water sources has been analysed in detail. The yield of each of the existing surface water reservoirs were analysed considering $80 \%$ reliability. Besides, analyses of the annual average water resources potential of the catchment areas that may be developed as additional sources of water supply to cater for the increasing water demand of the city were also conducted.

Comparison of water demand and supply were carried out, to understand the current situation and future water supply challenges. Such information could help the water authorities to make informed decisions and device a roadmap for sustainable management and development of the water resources. The comparison process was based on the two population growth scenarios i.e. moderate-growth rate and high-growth-rate and also on certain development scenario of the new catchments identified as potential sources of water for the city.

The results of the analysis showed that for the moderate growth rate scenario the water crisis could be managed through systematic development of the new catchments areas up to 2040 as shown in Table 3 and Figure 11. Minimizing leakage losses and introduction of effective and efficient water governance from source up to the point of end-users would play crucial role to close the gap between the available water resources for supply and water demand.

Table 3. Water demand and supply situation for moderate-growth rate

\begin{tabular}{cccl}
\hline Year & Annual Demand (Mcum) & Annual Supply (Mcum) & Assumed Water Supply \\
\hline 2010 & 9.2 & 15.5 & Sxisting Reservoirs \\
2015 & 14.4 & 15.5 & Existing Reservoirs \\
2020 & 19.0 & 23.5 & Existing Reservoirs + Demsebay \\
2025 & 23.1 & 26.5 & Existing Reservoirs + Demsebay + Ababruk \\
2030 & 26.8 & 32.5 & Existing Reservoirs + Demsebay + Ababruk + Ungula \\
2040 & 33.3 & 32.5 & Existing Reservoirs + Demsebay + Ababruk + Ungula \\
2050 & 43.5 & 32.5 & Existing Reservoirs + Demsebay + Ababruk + Ungula \\
2060 & 50.0 & 32.5 & Existing Reservoirs + Demsebay + Ababruk + Ungula \\
\hline
\end{tabular}

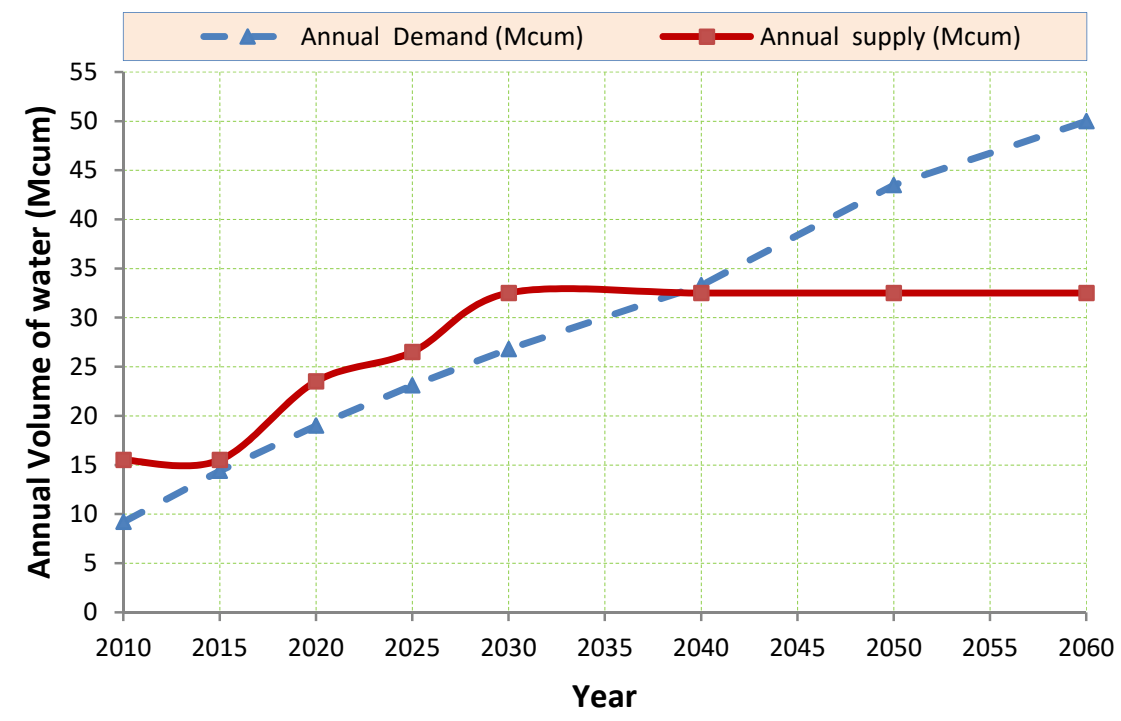

Figure 11. Water demand and supply comparison for moderate-growth rate

Assuming the high growth rate scenario of population as predicted by UN 2013, the gap between demand and supply will be wider and more critical. The analysis as indicated in Table 4 and Figure 12 predicted that the water crisis would be so critical. The water authorities should plan and consider systematic development of the new catchments areas identified for water supply immediately. 
Table 4. Water demand and supply comparison for high-growth rate scenario

\begin{tabular}{cccl}
\hline Year & Annual Demand (Mcum) & Annual supply (Mcum) & Development Scenario of Water Supply Sources \\
\hline 2010 & 12.6 & 15.5 & Existing Reservoirs \\
2015 & 20.0 & 15.5 & Existing Reservoirs \\
2020 & 27.0 & 23.5 & Existing Reservoirs + Demsebay \\
2025 & 33.0 & 26.5 & Existing Reservoirs + Demsebay + Ababruk \\
2030 & 38.8 & 32.5 & Existing Reservoirs + Demsebay + Ababruk + Ungula \\
2040 & 49.6 & 32.5 & Existing Reservoirs + Demsebay + Ababruk + Ungula \\
2050 & 68.4 & 32.5 & Existing Reservoirs + Demsebay + Ababruk + Ungula \\
2060 & 81.7 & 32.5 & Existing Reservoirs + Demsebay + Ababruk + Ungula \\
\hline
\end{tabular}

Exploration of new water sources outside the Central Regional administration but not very far from Asmara may also be considered as a long term solution to the water crisis. Another important issue that must be considered in this context would be to modernize the overall management system of the water utility and improve the efficiency of the water supply distribution system by controlling and minimizing leakage losses and other forms of Non-revenue water.

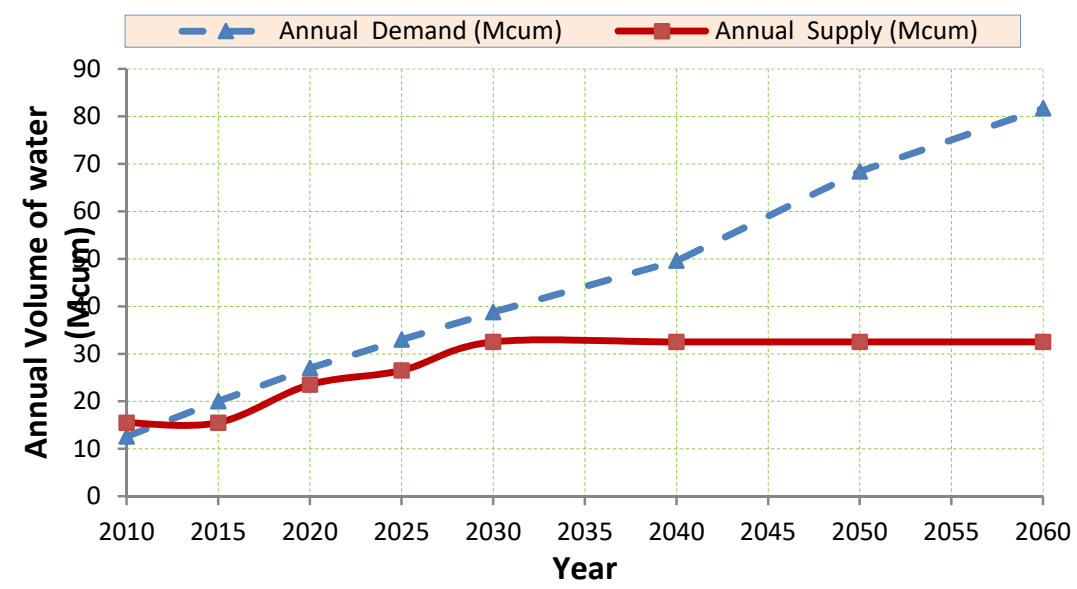

Figure 12. Water demand and supply comparison for high-growth rate

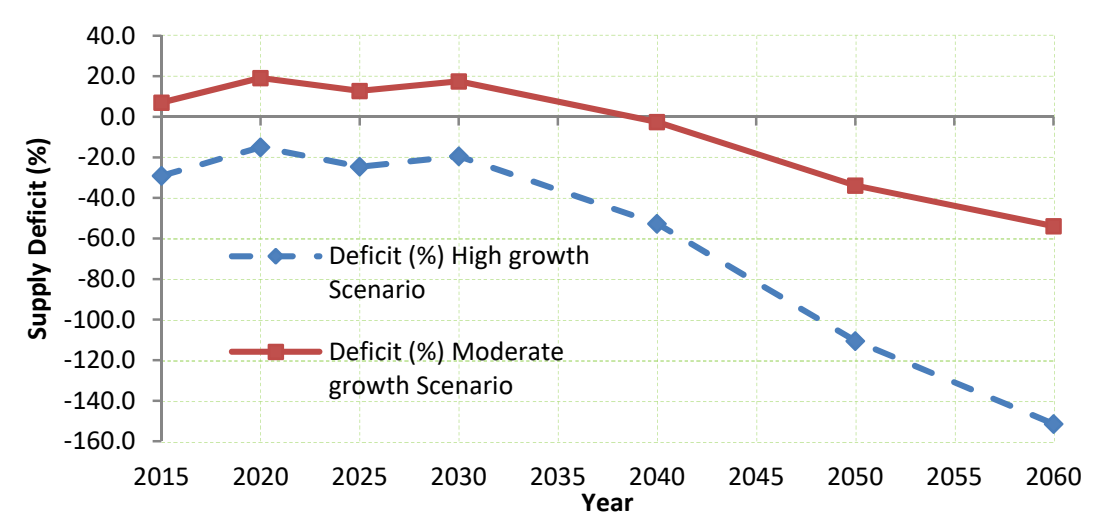

Figure 13. Prediction of water supply deficit in Asmara

The comparative analysis results between water available for supply and demand in the time period from 2015 to 2060 predicted very critical shortage of water in the Greater Asmara Area. Figure 13 shows the gap between supply and demand in terms of water supply deficit for the high and moderate population growth rate and based on the assumption of the development of new sources. 
The UN-population report (2013) indicated that Eritrea is one of countries in Africa with high population growth rate. Hence, in this case the high growth rate is the most likely scenario and creates the most critical situation for planning, design and development. It is also the most critical condition in terms of water demand, development of infrastructure, and financial investment and as such requires serious consideration by policy and decision makers in Eritrea in general and in Asmara in particular.

\section{Conclusion}

Water has become increasingly scarce and less reliable due to factors such as population growth, economic growth, increased urbanization and inefficient water management system and the supply is shrinking due to changing climatic patterns. The challenge of servicing more people with scarcer water resources is going to become a norm rather than an exception for AWSD and the situation requires critical appraisal of current perspective on urban water management. Policy and decision makers in the region, and managers of AWSD need to consider efficient water use practices and develop technical and management strategies that can respond to all these challenges simultaneously.

Population projections can alert policymakers to major trends that may affect economic development and help them develop policies that can be adapted for various projection scenarios. However, it is not possible to tell the future condition accurately and that is why users of population projections need to understand the reliability and the limitations of projection scenarios. Awareness of how projections are prepared and the possible sources of uncertainty in the numbers can help policymakers more effectively incorporate projections in their planning process.

In this study, the water supply yield of each of the existing surface water reservoirs were analysed with a water-balance model considering $80 \%$ reliability. Besides, analyses of the annual average water supply potential of the new catchment areas were conducted at $80 \%$ of probability of exceedance. The water demand and supply comparison was made on the basis of two population growth scenarios (moderate-growth rate and high-growth-rate) and on assumed development scenarios of the new catchments.

The following conclusion can be made:

- The water-balance model developed with a Visual Basic programming language can be used successfully as a management and decision making tool to predict the safe yield and corresponding reliability of the existing water supply reservoirs

- For the moderate growth rate scenario the predicted gap between water demand and supply may be managed through systematic development of the new catchment areas up to 2040 (annual supply of $32 \mathrm{x}$ $10^{6} \mathrm{~m}^{3}$ against annual demand of $33 \times 10^{6} \mathrm{~m}^{3}$ ).

- For the high growth rate scenario the water crisis is predicted to reach a serious level in the near future (annual supply of $24 \times 10^{6} \mathrm{~m}^{3}$ against annual demand of $27 \times 10^{6} \mathrm{~m}^{3}$ predicted in 2020). This scenario calls for development of the new catchment areas and treatment facilities much earlier as well as introduction of appropriate demand management measures.

- To close the gap between the available water supply and increasing water demand, utmost attention is needed by the decision making authorities and the management of the water utility to improve performance efficiency of the water supply system by instituting effective water governance and reducing leakage losses.

\section{Reference}

Ahmed, G. L., Srivastava, D. K., \& Rani, D. (2013). Optimization - Simulation Models For Yield Assessment of a Single Reservoir System. Journal of Indian Water Resources Society, 33(4), 9-16.

Asefa, T., Adams, A., \& Wanakule, N. (2015). A Level-of-Service Concept for Planning Future Water Supply Projects under Probabilistic Demand and Supply Framework. JAWRA Journal of the American Water Resources Association, 51(5), 1272-1285. https://doi.org/10.1111/1752-1688.12309

Ethiopia Water Supply and Sewerage Authority. (1985). Asmara Water Supply Feasibility Study (Volume 1: Main report).

Fiseha, B. M., Setegn, S. G., Melesse, A. M., Volpi, E., \& Fiori, A. (2010). Hydrological analysis of the Upper Tiber River Basin, Central Italy: a watershed modelling approach. HYDROLOGICAL PROCESSES Hydrol. Process. (2012), 2274(November 2008), 2267-2274. https://doi.org/10.1002/hyp

McMahon, T. a., Pegram, G. G. S., Vogel, R. M., \& Peel, M. C. (2007). Revisiting reservoir storage-yield relationships using a global streamflow database. Advances in Water Resources, 30(8), 1858-1872. https://doi.org/10.1016/j.advwatres.2007.02.003 
Mutunga, C., Zulu, E., \& De Souza, R.-M. (2012). Population Dynamics, Climate Change, and Sustainable Development in Africa.

Nauges, C., \& Whittington, D. (2009). Estimation of Water Demand in Developing Countries: An Overview. The World Bank Research Observer, 25(2), 263-294. https://doi.org/10.1093/wbro/lkp016

Neitsch, S., Arnold, J., Kiniry, J., \& Williams, J. (2011). Soil \& Water Assessment Tool Theoretical Documentation Version 2009, 1-647.

Okeola, O. G., Balogun, S. O., \& Bell, S. (2015). Estimating a municipal water supply reliability. Cogent Engineering, 2(1), 10. https://doi.org/10.1080/23311916.2015.1012988

SAUR Intenational and BRL ingenierie. (1997). Technical and Institutional Rehabilitation Study of Asmara Water Supply System. Administration of Central Region (Department of Infrastructure) Asmara 1997.

Tewolde, M. G., \& Cabral, P. (2011). Urban sprawl analysis and modeling in Asmara, Eritrea. Remote Sensing, 3(10), 2148-2165. https://doi.org/10.3390/rs3102148

UN. (2013). United Nations, Department of Economic and Social Affairs, Population Division (2013). World Population Prospects: The 2012 Revision, Volume I: Comprehensive Tables ST/ESA/SER.A/336. (Vol. I).

UN-Habitat. (2014). THE STATE OF AFRICAN CITIES 2014: Re-imagining sustainable urban transitions.

Vogel, R. M., \& Bolognese, R. A. (1995). Storage-reliability-resilience-yield relations for over-year water supply systems. Water Resources Research. https://doi.org/10.1029/94WR02972

Vogel, R. M., Sieber, J., Archfield, S. a., Smith, M. P., Apse, C. D., \& Huber-Lee, A. (2007). Relations among storage, yield, and instream flow. Water Resources Research, 43(5), 1-12. https://doi.org/10.1029/2006 WR005226

Yunus, S. D., \& Fidelia, N. N. (2012). Reservoir storage variations from hydrological mass balance and satellite radar altimetry. International Journal of Water Resources and Environmental Engineering, 4(6), $201-207$. https://doi.org/10.5897/IJWREE11.140

Zeraebruk, K., Mayabi, A., Gathenya, J., \& Zemenfes, T. (2014). Assessment of Level and Quality of Water Supply Service Delivery for Development of Decision Support Tools: Case Study Asmara Water Supply. International Journal of Sciences: Basic and Applied Research (IJSBAR), 14(1), 93-107.

Zeraebruk, K. N., Mayabi, A. O., Gathenya, J. M., \& Tsige, Z. (2014). Assessment of Water Supply Services and Operational Performance of Asmara Water Supply Department (AWSD) for Development of Decision Support Tools. Environment and Natural Resources Research, 4(4), 208-222. https://doi.org/10.5539/ enrr.v4n4p208

\section{Copyrights}

Copyright for this article is retained by the author(s), with first publication rights granted to the journal.

This is an open-access article distributed under the terms and conditions of the Creative Commons Attribution license (http://creativecommons.org/licenses/by/4.0/). 